\title{
Ultrasound for Critical Care Physicians: The Big Squeeze
}

A 57 year-old man without significant past medical history presented with difficulty swallowing and pleuritic chest pain. He was undergoing evaluation for his dysphagia when he was noted to be tachycardic and hypotensive shortly after admission to the medical-surgical ward. His initial chest x-ray revealed bilateral pleural effusions and what appeared to be cardiomegaly. A cardiac ultrasound was performed (Figure 1).

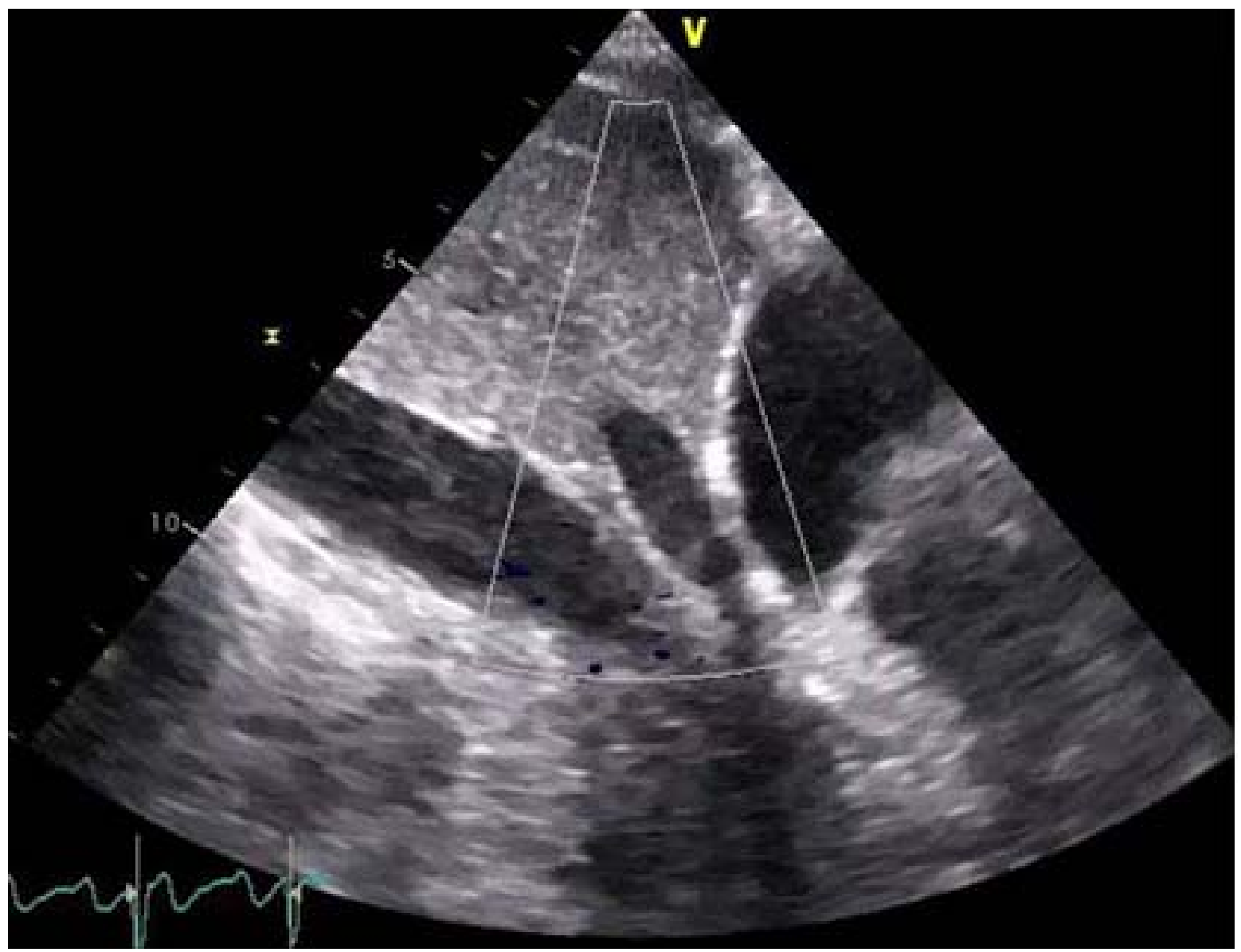

Figure 1. Subxiphoid view of patient's heart, inferior vena cava and hepatic vein.

What is the cause of the patient's tachycardia and hypotension?
1. Aortic dissection
2. Cardiac tamponade
3. Cardiomyopathy
4. Mitral insufficiency
5. Pulmonary embolus 


\section{Correct!}

\section{Cardiac tamponade}

The echocardiogram revealed a large pericardial effusion. There was diastolic flow reversal with expiration in the hepatic vein and inferior vena cava, and a pendulous heart within the pericardial cavity (Figures 1 and 2).

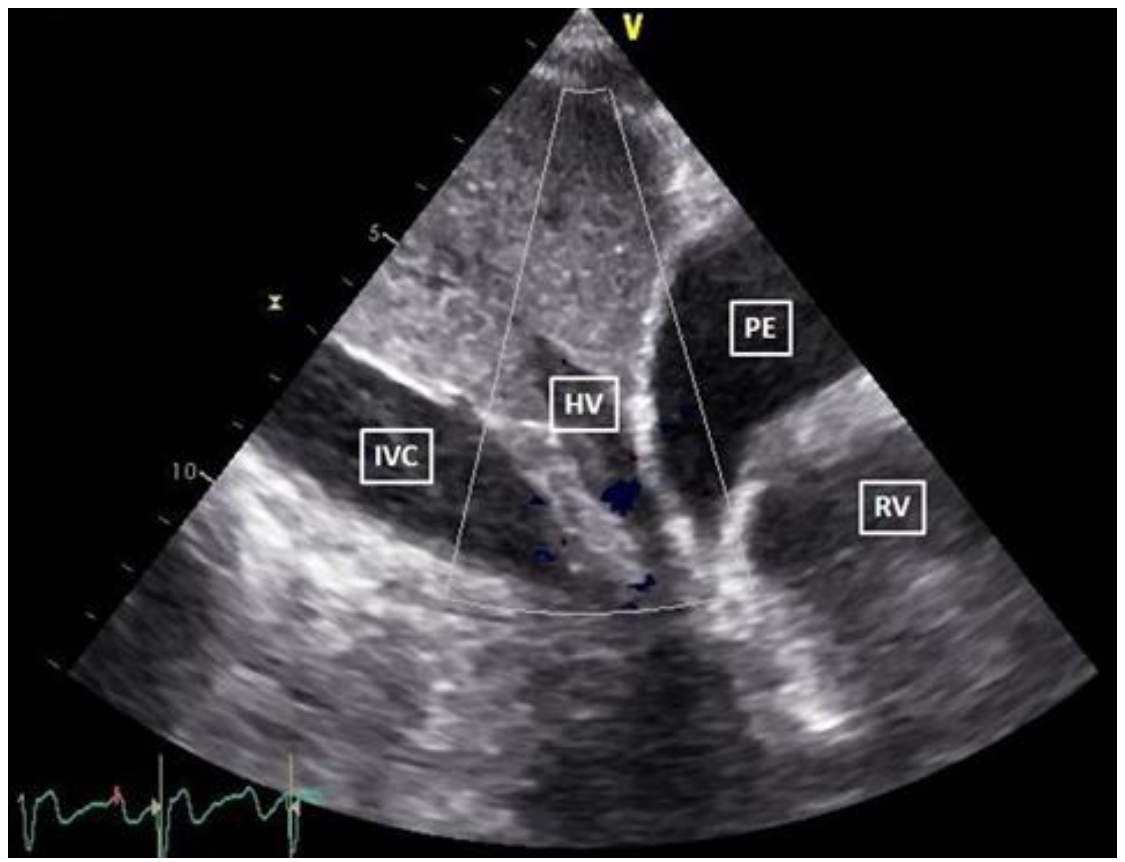

Figure 2. Static subxiphoid view showing the inferior vena cava (IVC), hepatic view $(\mathrm{HV})$, pericardial effusion (PE) and right ventricle (RV).

Additionally, there was diastolic compression of the right ventricle. The patient's pericardial effusion was ultimately attributed to malignancy.

Cardiac tamponade may result in the collapse of any of the cardiac chambers, however right-sided collapse is more common as the right heart is a more compliant structure. Left atrial collapse is a specific finding for tamponade. Irregular and augmented respiratory variation of the mitral and tricuspid velocities is common in tamponade physiology. Hepatic vein flow blunting or reversal have high positive and negative predictive values for tamponade.

Tauseef Siddiqi, MD; Seth Assar, MD; Joshua Malo, MD

The University of Arizona College of Medicine at South Campus, Tucson, Arizona

\section{Reference}

Oh, J.K., Seward, J.B. and Tajik, A.J. (2007) Pericardial Diseases. In: Oh, J.K., Seward, J.B. and Tajik, A.J., Eds., The Echo Manual, 3rd Edition, Lippincott, Williams \& Wilkins, Philadelphia, 226-242. 